\title{
Optical Nanoprobes for Ultrasensitive Immunoassay
}

 \\ ${ }^{\dagger}$ School of Chemistry and Chemical Engineering, Yantai University, Yantai, Shandong 264005, China \\ ${ }^{\ddagger}$ Key Laboratory of Coastal Environmental Processes and Ecological Remediation, Yantai Institute of Coastal Zone Research, Chinese \\ Academy of Sciences, Yantai, Shandong 264003, China \\ ${ }^{\S}$ Department of Bionanotechnology, Hanyang University, Ansan, Gyeonggi 426-791, South Korea
}

\section{CONTENTS}

Properties and Surface Functionalization of Nanomaterials

Localized Surface Plasmon Resonance (LSPR)

Properties of Nanomaterials

Fluorescence Properties of Nanomaterials

Surface-Enhanced Raman Scattering Properties

of Nanomaterials

Surface Functionalization of Nanomaterials

Noncovalent Modifications

Covalent Binding or Affinity-Based Methods

Typical Optical Sensing Strategies

Colorimetric Sensing Strategies

Aggregation or Antiaggregation-Based Methods

Single Particle Morphology-Based Methods

Enzyme-Mediated Methods

Fluorescence Sensing Strategies

"Turn off" Type

"Turn on" Type

Surface-Enhanced Raman Scattering Strategies

Analyte-Induced SERS Nanoprobe Aggrega-

tion/Antiaggregation

SERS-Nanoprobe-Based Optical Labeling

Challenges and Perspectives

Author Information

Corresponding Authors

ORCID

Notes

Biographies

Acknowledgments

References

124

125

125

126

126

127

128

128

$\mathrm{N}$ anomaterials exhibit unique physical and chemical properties that make them excellent scaffolds for the fabrication of novel optical nanoprobes. As a result of the properties afforded by the highly tunable size and shapedependent features of nanomaterials, their large surface-tovolume ratios, and their conjugations with desired specificity or assemblies with desired signal transduction mechanisms, nanomaterial-based sensors can markedly improve the sensitivity and specificity of analyte detection. ${ }^{1-3}$ These unique properties of nanomaterials, as well as their overall structural robustness, make them highly amenable for use in various sensor platforms. Accordingly, myriad nanomaterial-based immunoassay approaches have been developed employing various kinds of nanomaterials such as noble metal nano- particles, ${ }^{4,5}$ quantum dots (QDs), ${ }^{6-8}$ upconversion nanomaterials, ${ }^{9,10}$ and carbon nanomaterials. ${ }^{11,12}$ In particular, enormous attention has been paid to the development of signal amplification strategies using optical nanoprobes in immunoassays in order to realize high sensitivity and selectivity for the detection of analytes. For instance, in the traditional sandwich-type immunoassay, an enzyme-labeled detection antibody is used as the indicator to amplify the detection signal. However, the sensitivity of this system is often limited because of the 1:1 ratio between the enzyme and the detection antibody. Nanomaterials and nanotechnology bring exciting new possibilities for the development of advanced optical immunoassay strategies. To achieve this goal, nanomaterials are usually employed (a) as supports for the loading of numerous indicators (e.g., biomolecules, fluorescent dyes, or Raman reporters) to amplify the recognition event through their high surface-to-volume ratio or (b) as the indicator that is generated with the aid of biochemical reactions to achieve multiple signal amplification. In this Review, we will focus on the most recent advances in the field of nanomaterial-based sensitive immunoassay. First, we will give a brief overview of the properties of nanomaterials (Figure 1) and basic modification methods. Next, we will introduce various novel types of high sensitivity nanomaterial-based optical immunosensors categorized by different signal detection strategies: colorimetry/UV-vis spectra, fluorometry, and surface-enhanced Raman scattering. Finally, we will present the challenges and provide some perspectives on the future trends of this field.

\section{PROPERTIES AND SURFACE FUNCTIONALIZATION OF NANOMATERIALS}

Localized Surface Plasmon Resonance (LSPR) Properties of Nanomaterials. One of the most remarkable properties of noble metal nanoparticles is their localized surface plasmon resonance (LSPR), which results from the collective coherent oscillation of conduction band electrons across the nanoparticles upon interaction with light at a specific resonant wavelength. ${ }^{13}$ The LSPR response of noble metal nanoparticles depends on their size, shape, interparticle distance, and morphology, as well as the dielectric environment. Consequently, controlling the morphology or the existing state of noble metal nanoparticles is a powerful method to control the

Special Issue: Fundamental and Applied Reviews in Analytical Chemistry 2017

Published: November 6, 2016 


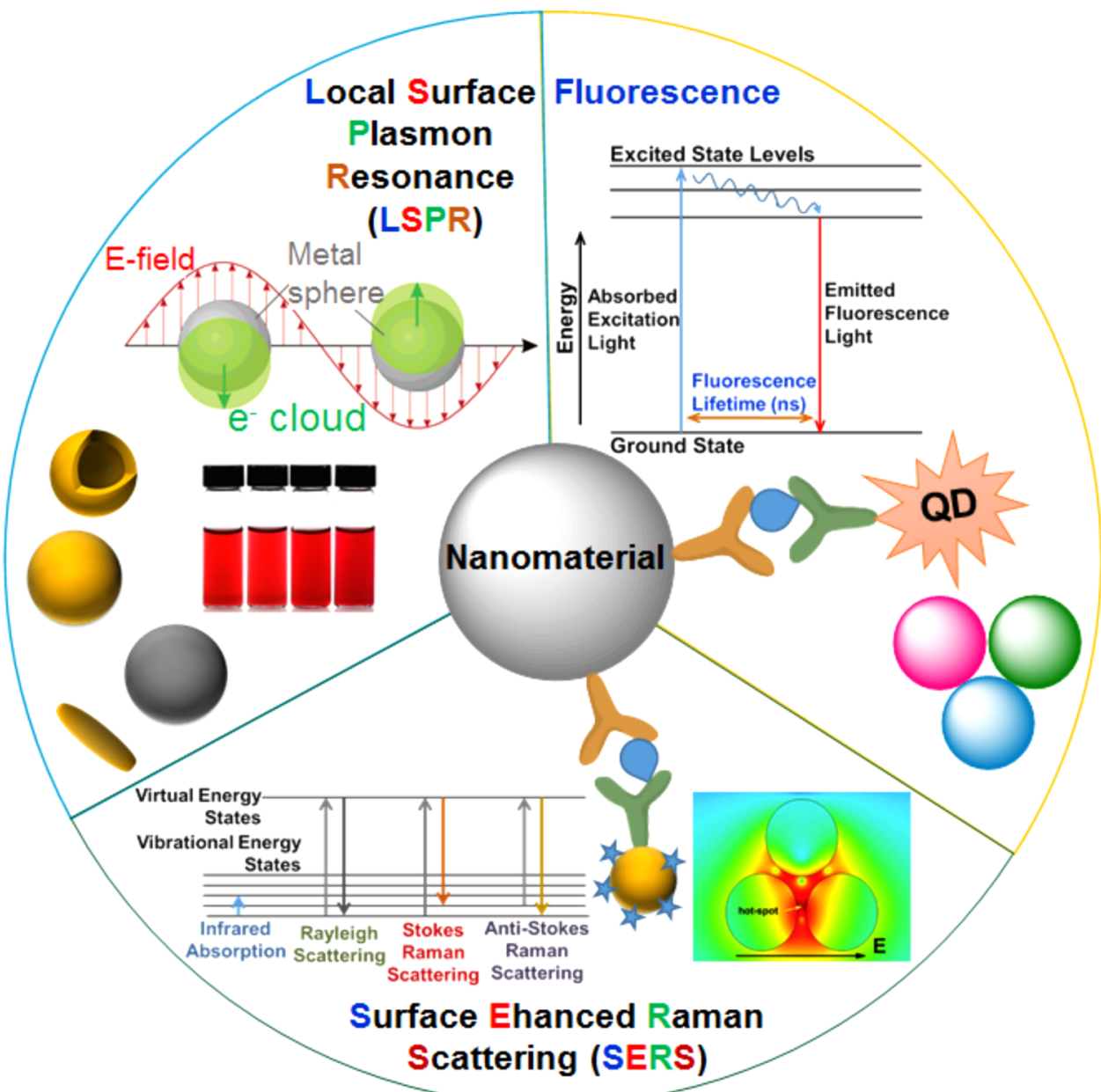

Figure 1. Properties of nanomaterials.

Table 1. List of Diverse Nanomaterials with Different Modification Methods

\begin{tabular}{|c|c|c|c|c|}
\hline nanomaterials & biomolecules & linking mode & type & reference \\
\hline AuNPs & antibody protein & physical adsorption & noncovalent binding & $18-20$ \\
\hline AuNPs & antibody protein & EDC-NHS interaction & covalent binding & $21-23$ \\
\hline AgNPs & DNA & $\mathrm{Ag}-\mathrm{S}$ interaction & covalent binding & 24 \\
\hline graphene oxide & antibody & EDC-NHS interaction & covalent binding & 25 \\
\hline carbon nanotube & antibody enzyme & EDC-NHS interaction & covalent binding & 26 \\
\hline upconversion nanoparticles & antibody & EDC-NHS interaction & covalent binding & 27 \\
\hline nanospherical poly(acrylic acid) brushes & antibody & EDC-NHS interaction & covalent binding & 28 \\
\hline $\mathrm{NH}_{2}$-functionalized magnetic nanoparticles & antibody & glutaraldehyde & covalent binding & 29 \\
\hline $\mathrm{COOH}$-functionalized magnetic nanoparticles & antibody & EDC-NHS interaction & covalent binding & 27,30 \\
\hline streptavidin functionalized magnetic nanoparticles & antibody DNA & biotin-avidin interaction & affinity binding & 31,32 \\
\hline streptavidin functionalized semiconductor QD & antibody & biotin-avidin interaction & affinity binding & 33,34 \\
\hline
\end{tabular}

LSPR response that can be used in the design of colorimetric sensing systems.

Fluorescence Properties of Nanomaterials. Another unique property that can be used for sensing applications is luminescence or fluorescence. Compared with conventional molecular probes like organic dyes and fluorescent proteins, luminescent nanomaterials ${ }^{7,9,14,15}$ (e.g., quantum dots [QDs], noble metal nanoclusters, upconversion nanomaterials, graphene oxides [GOs]/graphene, and carbon nanoparticles [CNPs]) possess attractive physicochemical features such as high luminescence efficiency, long lifetime, large Stokes and/or anti-Stokes shifts, narrow emission bands, and high resistance to photobleaching, depending on their size, shape, and composition. Moreover, some nanomaterials have the characteristic of fluorescence quenching, which occurs when the emission spectrum of the fluorophore overlaps with the surface plasmon band of the nanomaterial.

Surface-Enhanced Raman Scattering Properties of Nanomaterials. Conventional Raman scattering is severely restricted by the low efficiency of inelastic photon scattering by molecules, which leads to a weak signal. However, Raman scattering intensity can be increased by up to $10-14$ orders of magnitude when reporter molecules are adsorbed on or near the nanoparticle surface. ${ }^{3}$ This Raman scattering amplification phenomenon is known as surface-enhanced Raman scattering (SERS) and is due to electromagnetic and chemical enhance- 
(A)

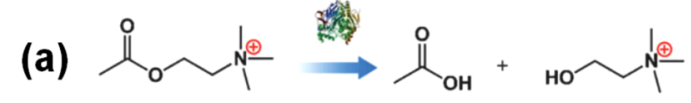

(b)
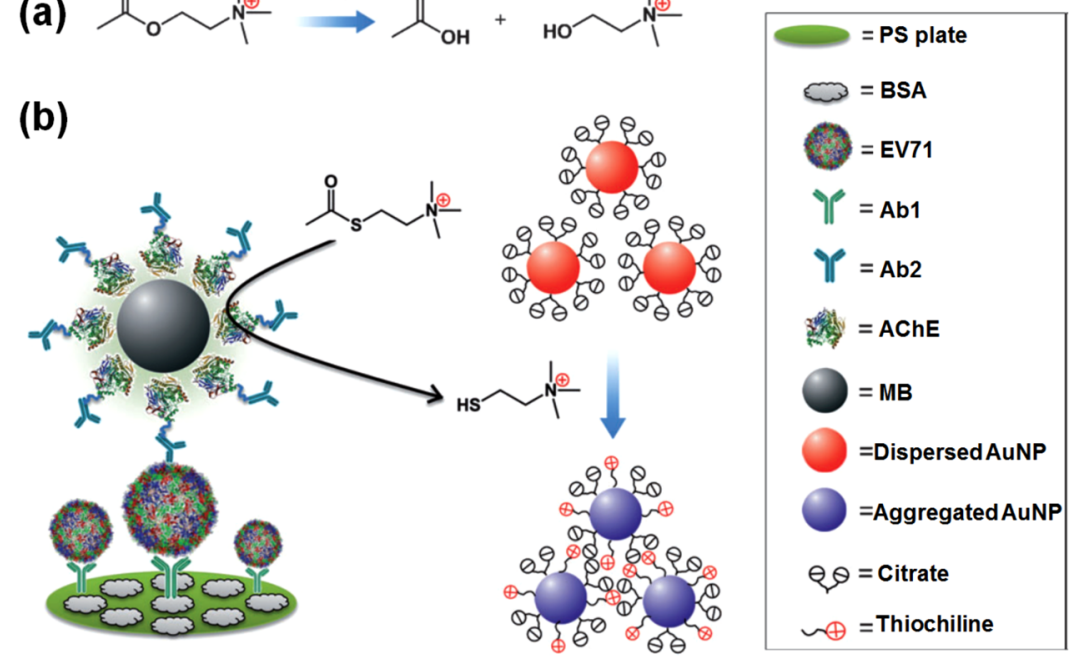

(B) Secondary Antibody-CuO NPs

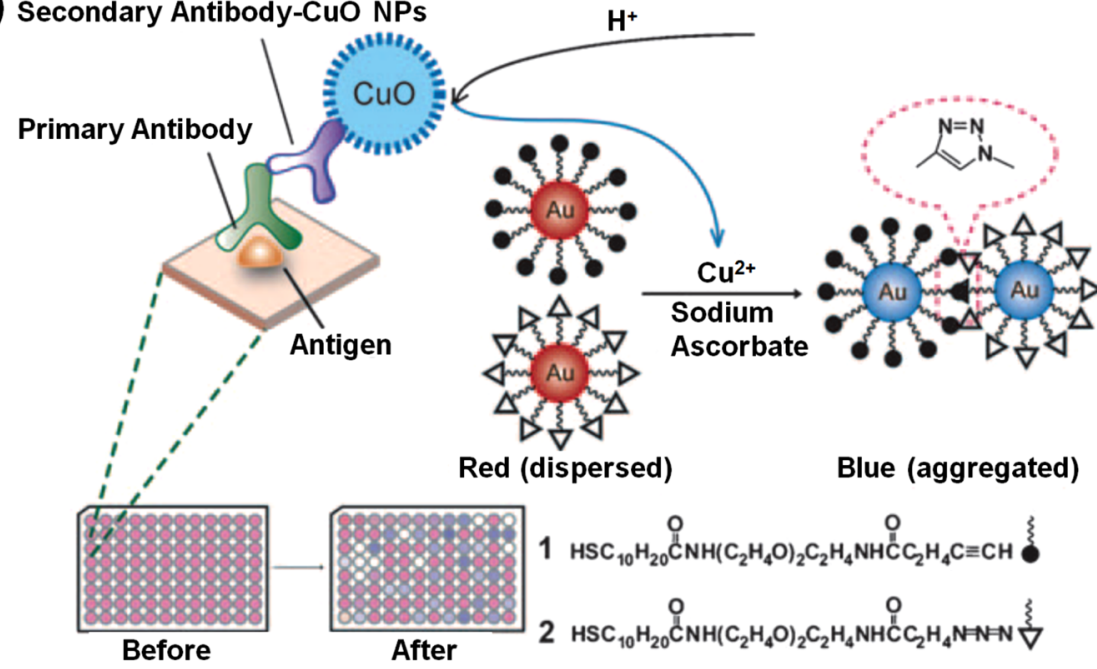

Figure 2. (A) Scheme of the colorimetric assay based on AChE-catalyzed hydrolysis reaction for the detection of enterovirus 71 (EV71). (a) AChE catalyzes the hydrolysis of acetylcholine to produce acetate and choline. (b) The improved sandwich ELISA format. EV71 is captured on the polystyrene (PS) substrate by a capture antibody $(\mathrm{Ab} 1)$ and is then recognized by a detection antibody (Ab2) that is preconjugated with $\mathrm{AChE}$ onto the magnetic beads (MB). After addition of acetylthiocholine (ATC) and citrate-capped AuNPs, AChE can catalyze the hydrolysis of ATC to produce thiocholine, resulting in the aggregation of AuNPs through electrostatic interaction. (Reprinted from Acetylcholinesterase-Catalyzed Hydrolysis Allows Ultrasensitive Detection of Pathogens with the Naked Eye, Liu, D. B.; Wang, Z. T.; Jin, A.; Huang, X. L.; Sun, X. L.; Wang, F.; Yan, Q.; Ge, S. X.; Xia, N. S.; Niu, G.; Liu, G.; Hight Walker, A. R.; Chen, X. Y. Angew. Chem. Int. Ed., Vol. 52, Issue 52 (ref 38). Copyright 2013 Wiley.) (B) Scheme of the copper-mediated amplification immunoassay. After the immune reaction, the labeled $\mathrm{CuO} \mathrm{NPs}$ are dissolved by $\mathrm{HCl}$ to release $\mathrm{Cu}$ (II). The $\mathrm{Cu}$ (II) has the ability to induce aggregation of AuNPs functionalized with azide and alkyne and thus can be used to reflect the concentration of the target. (Reprinted from Copper-Mediated Amplification Allows Readout of Immunoassays by the Naked Eye, Qu, W. S.; Liu, Y. Y.; Liu, D. B.; Wang, Z.; Jiang, X. Y. Angew. Chem. Int. Ed., Vol. 50, Issue 15 (ref 39). Copyright 2011 Wiley.)

ment effects, which are dependent on the size, shape, orientation, and aggregation of the nanoparticle.

Surface Functionalization of Nanomaterials. The unique properties described above have led to a strong interest in the use of nanomaterials in a variety of immunosensors. To endow nanomaterials with sensing capabilities, a suitable method should be introduced to functionalize them with recognition elements or/and signal triggering elements in order to enhance the selectivity and sensitivity. ${ }^{16,17}$ Various techniques have been explored to functionalize nanomaterials and are generally divided into two categories, noncovalent modifications and covalent binding or affinity-based methods, as shown in Table 1 . Here, we briefly discuss noncovalent and covalent strategies for modifying nanomaterials.

Noncovalent Modifications. Noncovalent modification via physical adsorption, $\pi-\pi$ stacking, or electrostatic interaction is a commonly used immobilization method for biomolecules such as antibodies, antigens, or enzymes that can avoid the need for any coupling reagents and reduce loss of the intrinsic properties of the original nanomaterials. However, the noncovalent approach has the following limitations: (i) less control over the number of attached biomolecules per nanoparticle, (ii) orientation of biomolecules, and (iii) desorption of biomolecules. 
(A)

\section{Plasmonic ELISA}

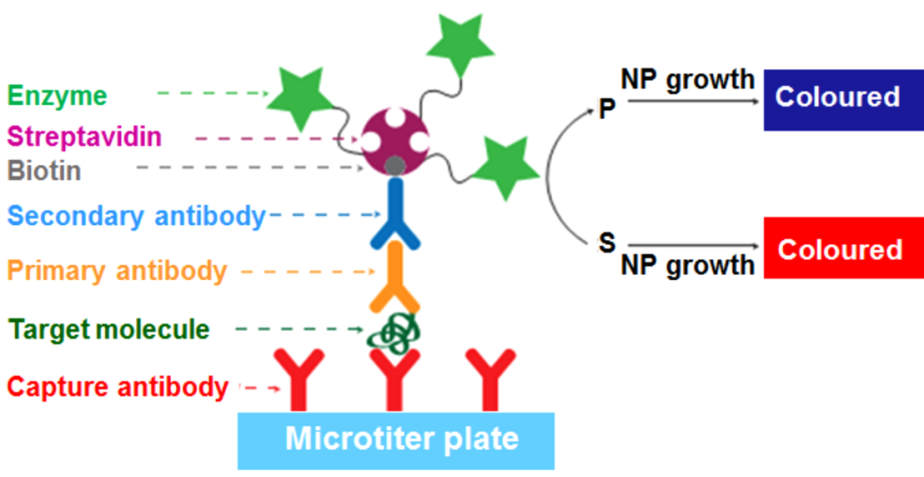

(B)

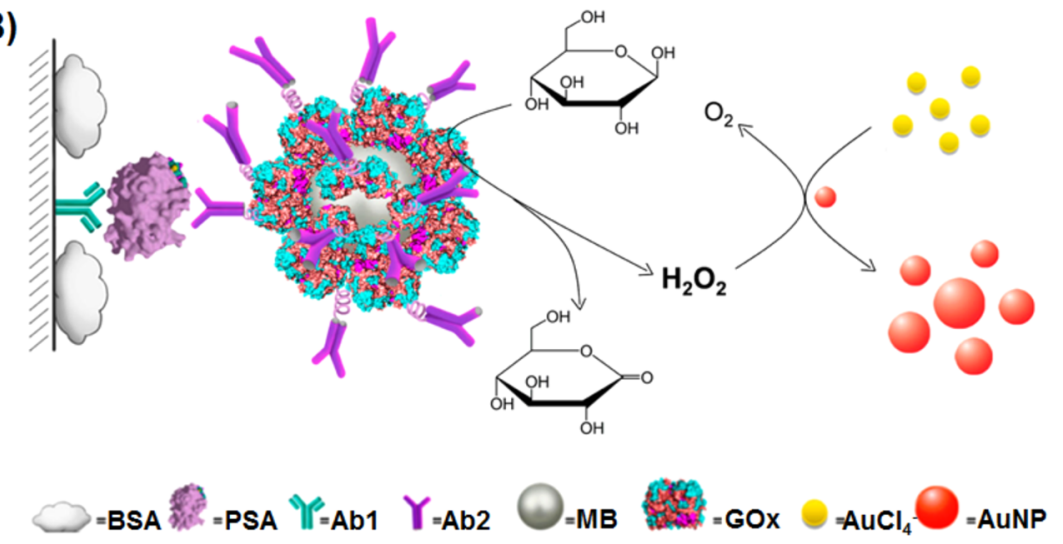

(C)

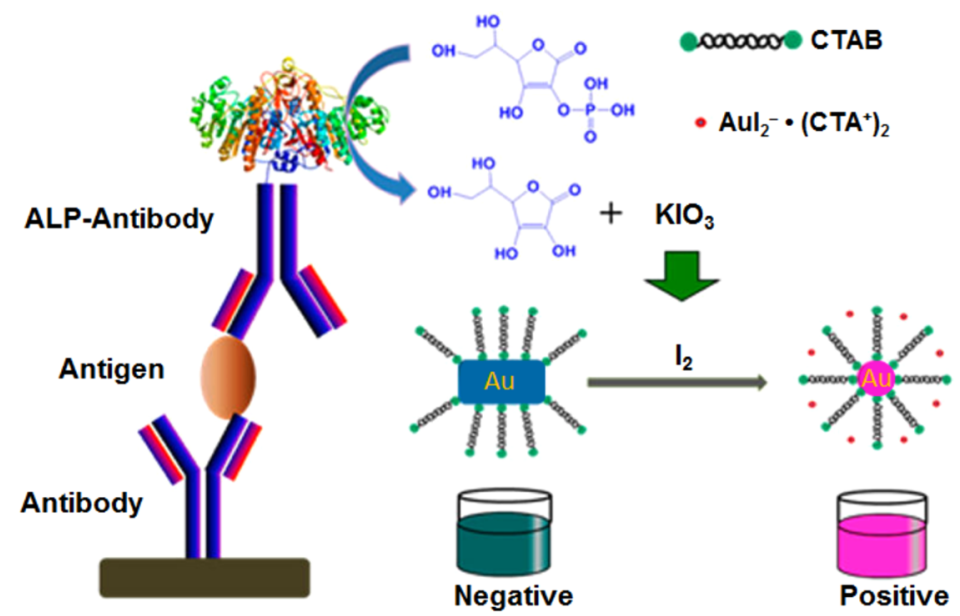

Figure 3. (A) Schematic illustration of signal generation mechanisms for the plasmonic sandwich ELISA format. After the sandwich ELISA process, the enzyme-labeled secondary antibodies are anchored to the substrate, and the biocatalytic cycle of the enzyme produces colored nanoparticle solutions of characteristic tonality (S, substrate; P, product; NP, nanoparticle). (Adapted from de la Rica, R.; Stevens, M. M. Nature Nanotechnol. 2012, 7, 821-824 (ref 40). Copyright 2012, with permission from Nature Publishing Group.) (B) Illustration of the colorimetric immunoassay based on glucose oxidase (GOx)-catalyzed growth of AuNPs. (Reproduced from Liu, D. B.; Yang, J.; Wang, H. F.; Wang, Z. L.; Huang, X. L.; Wang, Z. T.; Niu, G.; Hight Walker, A. R.; Chen, X. Y. Anal. Chem. 2014, 86, 5800-5806 (ref 42). Copyright 2014 American Chemical Society.) (C) Schematic representation of the visual plasmonic ELISA based on iodine-mediated etching of AuNRs. (Reproduced from Zhang, Z. Y.; Chen, Z. P.; Wang, S. S.; Cheng, F. B.; Chen, L. X. ACS Appl. Mater. Interfaces 2015, 7, 27639-27645 (ref 44). Copyright 2015 American Chemical Society.)

Covalent Binding or Affinity-Based Methods. Compared with noncovalent methods, covalent binding or affinity-based methods are preferred as they avoid the limitations mentioned above and can effectively, stably, and specifically install functionalities. This is because covalent binding and affinitybased strategies can control chemisorption via covalent binding, which can effectively avoid nonspecific physisorption. Moreover, the number of functional groups can be controlled by fine-tuning the functionalization processes. For instance, Mirkin's group modified antibody labeled gold nanoparticles (AuNPs) with alkylthiol-capped bar-code DNA via the $\mathrm{Au}-\mathrm{S}$ interactions, successfully synthesizing antibody labeled AuNPs 
with high loading ratio of DNA which was a substantial amplification of the detection signal. ${ }^{35}$ Besides, they fabricated a type of polyvalent ( $3^{\prime}$-propylthiol- $\mathrm{T}_{24}$-decanoic acid) oligonucleotide functionalized AuNPs through $\mathrm{Au}-\mathrm{S}$ interactions, which were used for further conjugation with antibodies via 1ethyl-3-(3-(dimethylamino)propyl) carbodiimide (EDC) and sulfo $\mathrm{N}$-hydroxysuccinimide (NHS). ${ }^{36,37}$ Compared with the previous work, this approach can not only provide maximum surface area for the AuNPs loading of oligonucleotide without the occupation of the AuNPs surface by adsorbed antibodies but also provide a stable AuNPs-based platform for the conjugation with antibody. Generally speaking, there are three widely used strategies for creating covalent functionalized nanomaterials: (1) using reactive ligands attached to the surface of nanomaterials, such as thiol-PEG-COOH or dihydrolipoic acid (DHLA); (2) using glutaraldehyde or EDC/NHS for amine or carboxylic functionalized nanomaterials; (3) through noble metal-thiol interactions. For affinity-based immobilization, the most commonly used method is through biotinavidin interaction. For example, streptavidin functionalized magnetic nanoparticles can be used for affinity binding of biotinylated biomolecules (e.g., biotinylated proteins or biotinylated oligonucleotides).

\section{TYPICAL OPTICAL SENSING STRATEGIES}

The ultrasensitive detection of biomolecules based on nanomaterials has received considerable attention due to their excellent advantages such as catalytic activity and biocompatibility that accelerate the signal transduction and allow high loading of signal tags to amplify recognition events. To achieve highly sensitive and specific biosensing, efficient analytical methods based on nanomaterials have been developed in the past decade. According to their signal detection formats, the current well-developed immunoassays based on nanomaterials can be divided into three broad categories: colorimetric/UVvis, fluorescence, and SERS immunoassay. In this section, we will highlight the applications of nanomaterials for immunoassay based on various optical detection modes.

Colorimetric Sensing Strategies. Nanomaterial-based colorimetric immunoassays are commonly based on a change in the optical properties of the nanomaterial due to aggregation or morphology transition or a color change produced by enzyme-assisted nanoparticle amplification. On the basis of the behavior of nanoparticles, colorimetric sensing strategies can be summarized as three types: the first is based on analyte-induced aggregation of nanoparticles and is called an aggregation-based method; the second is based on the morphology transition of single particles and is called a single particle morphology-based method; the third primarily uses the nanoparticles as a substrate for loading enzyme labels and is called an enzyme-mediated method.

Aggregation or Antiaggregation-Based Methods. The aggregation of noble metal nanoparticles such as gold and silver nanoparticles induces interparticle plasmon coupling, leading to a change in their color and absorbance. Colorimetric sensing based on color (absorbance) changes during nanoparticle aggregation is highly dependent on their distance, concentration, and the nature and density of the recognition elements. For example, Chen's group developed a colorimetric assay with an ultrahigh sensitivity for pathogen detection based on an improved heterogeneous sandwich type enzyme-linked immunosorbent assay (ELISA) through an acetylcholinesterase (AChE)-catalyzed hydrolysis reaction, as shown in Figure $2 \mathrm{~A}^{38}$
In this study, the detection sensitivity was comparable to that of polymerase chain reaction (PCR) as a result of two rounds of amplification. First, detection antibodies (denoted as Ab2) were coated on the surface of magnetic beads (MBs) through conjugation between $\mathrm{AChE}$ and MBs. The AChE can catalyze conversion of its substrate acetylthiocholine to positively charged thiocholine, resulting in the aggregation of negatively charged citrate-capped gold nanoparticles (citrate-AuNPs) through electrostatic interactions. Second, one MB can load thousands of molecules of AChE and Ab2, which can specifically recognize the analyte through the antibody-analyte reaction. Using MBs as the substrate for loading AChE and $\mathrm{Ab} 2$, very small amounts of the analyte can be detected because of the high density of AChE on MB.

Jiang's group developed a colorimetric immunoassay based on $\mathrm{Cu}(\mathrm{I})$-catalyzed click chemistry through azide- and alkynemodified gold nanoparticles (AuNPs) (Figure 2B). ${ }^{39}$ Here, the second antibodies were labeled by copper monoxide nanoparticles ( $\mathrm{CuO}$ NPs), which could be indirectly captured by the target antigen. After the reaction, $\mathrm{CuO}$ NPs were dissolved to produce $\mathrm{Cu}(\mathrm{II})$. The $\mathrm{Cu}(\mathrm{II})$ was further reduced to $\mathrm{Cu}(\mathrm{I})$ by sodium ascorbate, which in turn can act as a catalyst thus inducing aggregation of AuNPs that are prefunctionalized with azide and alkyne groups. This method only needs a small amount of $\mathrm{Cu}(\mathrm{I})$ as catalyst due to the nature of the coppercatalyzed reaction, ensuring the high selectivity and sensitivity of the immunoassay.

Single Particle Morphology-Based Methods. In addition to the change in distance, change in size is another attractive strategy for designing colorimetric sensors. For instance, a signal generation mechanism based on enzymatic control of the growth of AuNPs was developed for ultrasensitive detection of protein in an ELISA assay (Figure 3A). ${ }^{40}$ In this approach, the target molecule was first captured by specific antibodies that were preimmobilized on a solid substrate and subsequently labeled with an enzyme via a second antibody. This enzyme can consume hydrogen peroxide, and its activity correlates with the growth of AuNPs to yield blue- or red-colored solutions in the presence or absence of the analyte. In the absence of the analyte, the gold ions are reduced rapidly in the presence of a high concentration of hydrogen peroxide, which favors the formation of spherical nonaggregated gold nanoparticles with a red color. However, in the presence of the analyte, the enzyme causes a reduction in the concentration of hydrogen peroxide, which results in an ill-defined morphology comprising aggregated nanoparticles with a blue color. The blue/red color change allows detection of the analyte with the naked eye. This plasmonic ELISA was applied for the detection of two model analytes (prostate specific antigen [PSA] and HIV-1 capsid antigen p24) at the ultralow concentration of $10^{-18} \mathrm{~g}$ $\mathrm{mL}^{-1}$ in whole serum. Although this approach is ultrasensitive for detecting analytes, quantification of the exact concentration of the target molecule is inaccurate. Therefore, further effort is necessary to improve the performance of this plasmonic ELISA approach.

Wang et al. established a simple method for amplified optical detection of mycotoxin aflatoxin $\mathrm{B} 1(\mathrm{AFB} 1)$ based on controlled homogeneous growth of immunogold in aqueous solution. ${ }^{41}$ Here, AFB1-BSA conjugate functionalized magnetic beads were used as capture probe, and anti-AFB1 antibody-modified AuNPs were employed as detection probe for immunological recognition of target AFB1. This immune reaction was further converted into the gold autocatalytic 
(A)
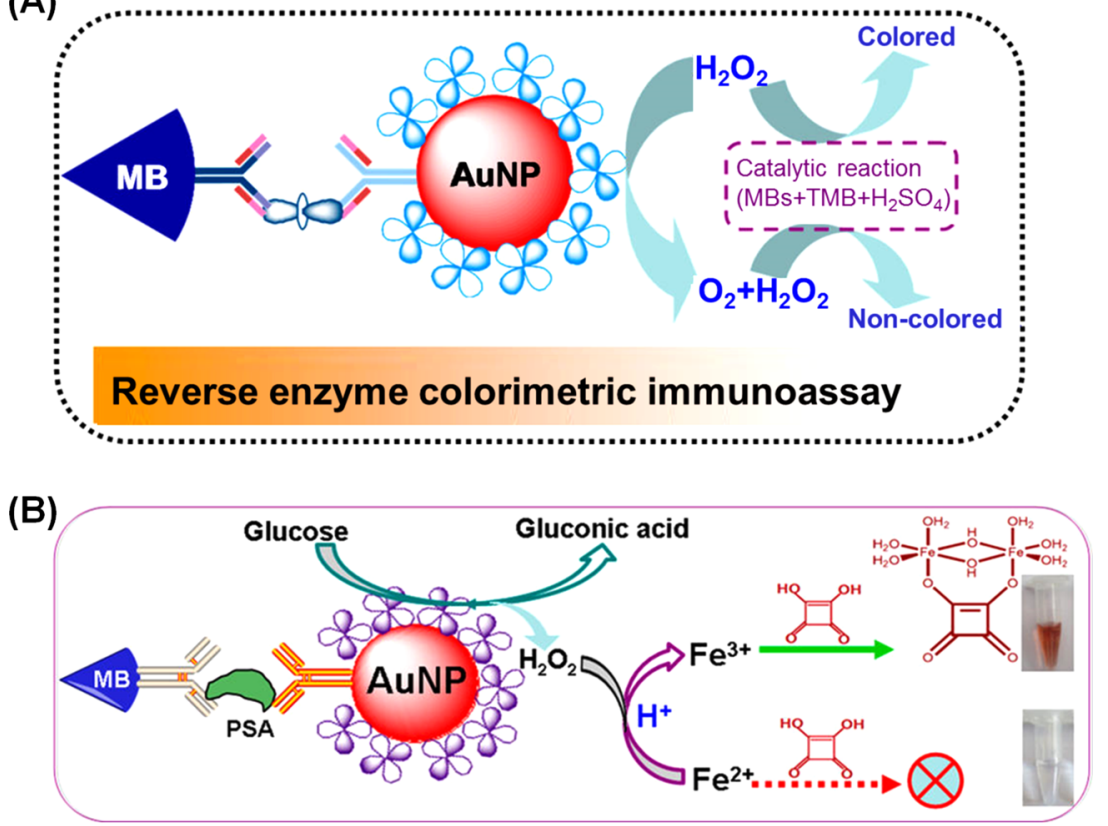

Figure 4. (A) Schematic representations of the magnetic bead enzyme-mediated reverse colorimetric immunosensing protocol. (Reproduced from Gao, Z. Q.; Xu, M. D.; Hou, L.; Chen, G. N.; Tang, D. P. Anal. Chem. 2013, 85, 6945-6952 (ref 29). Copyright 2013 American Chemical Society.) (B) Schematic representation of the colorimetric immunoassay with signal amplification based on a new enzyme-chromogenic substrate system. (Reprinted from Lai, W. Q.; Tang, D. P.; Zhuang, J. Y.; Chen, G. N.; Yang, H. H. Anal. Chem. 2014, 86, 5061-5068 (ref 19). Copyright 2014 American Chemical Society.)

enlargement signal in the aid of hexadecyltrimethylammonium bromide, ascorbic acid, and sodium thiosulfate. On the basis of the above principle, a high sensitivity for AFB1 was achieved with a lower detection limit of $7 \mathrm{pg} \mathrm{mL}^{-1}$.

In another example, Chen's group designed a quantitative colorimetric immunoassay based on glucose oxidase (GOx)catalyzed growth of small AuNPs $(5 \mathrm{~nm})$ that allows detection of cancer biomarkers at attomolar levels in clinical samples (Figure 3B). ${ }^{42}$ The researchers noted that a solution containing a low concentration $(<10 \mathrm{nM})$ of $5 \mathrm{~nm}$ AuNP is normally colorless, whereas a solution of larger AuNPs at the same concentration is typically red. This color emergence can be easily distinguished by the naked eye. Using this phenomenon, they employed a detection antibody (Ab2)/GOx functionalized $\mathrm{MBs}(\mathrm{Ab} 2-\mathrm{GOx}-\mathrm{MBs})$ complex as the detection probe. In the presence of target, the $\mathrm{Ab} 2-\mathrm{GOx}-\mathrm{MB}$ conjugates can be captured through immunoreaction. The GOx can catalyze the oxidation of glucose to produce $\mathrm{H}_{2} \mathrm{O}_{2}$, which induces the growth of $5 \mathrm{~nm}$ AuNPs with the aid of $\mathrm{AuCl}_{4}{ }^{-}$and causes the colorless AuNP solution to turn red together with a change in the absorption band. This colorimetric strategy provided a highly sensitive method for PSA with a limit of detection of 93 $\mathrm{aM}$, more than 4 orders of magnitude greater than that of the commercial ELISA assay (6.3 pM).

Our group developed an ELISA-like assay based on goldenhanced peroxidase-like activity of AuNPs with sensitive detection with the naked eye. ${ }^{43}$ In this method, goat antihuman IgG antibody (anti-IgG) was used as the capture antibody and AuNP-labeled anti-IgG acted as the detection antibody. In the presence of human IgG (H-IgG), the anti-IgG-H-IgG-AuNPlabeled anti-IgG could form a sandwich structure. After addition of $\mathrm{HAuCl}_{4} \cdot 4 \mathrm{H}_{2} \mathrm{O}$ and $\mathrm{NH}_{2} \mathrm{OH} \cdot \mathrm{HCl}$, a new gold shell was formed on the surface of AuNPs, which significantly enhanced the peroxidase-like catalytic ability of AuNPs against the substrate $3,3^{\prime}, 5,5^{\prime}$-tetramethylbenzidine (TMB) resulting in a bright blue color. This colorimetric immunoassay could detect $\mathrm{H}$-IgG at concentrations as low as $0.3 \mathrm{ng} \mathrm{mL}^{-1}$. In addition, we also reported a plasmonic ELISA based on colorimetric detection of alkaline phosphatase (ALP) through iodinemediated etching of gold nanorods (AuNRs) (Figure 3C). ${ }^{44}$ As the intermediate of the enzyme-triggered reaction, iodine etches AuNRs into $\mathrm{Au}(\mathrm{I})$ and leads to a blue-shift of the LSPR of AuNRs. The peak shift can be used for quantification of human immunoglobulin $\mathrm{G}$ (IgG), which was chosen as a model protein in this study. The detection limit for IgG was calculated to be $100 \mathrm{pg} \mathrm{mL}^{-1}$, which is much lower than that of other similar methods and comparable to the results obtained from many sensitive electrochemical methods. Successful detection of human IgG in fetal bovine serum indicates that this method is applicable to the determination of low abundance proteins in complex biological samples.

Enzyme-Mediated Methods. The very high surface area-tovolume ratio of nanomaterials makes them promising candidates for ultrasensitive probes for immunoassay due to signal amplification.

Gao et al. reported a reverse colorimetric immunoassay (RCIA) platform for the sensitive detection of biomolecules (PSA) by combining the highly catalytic activity of catalase (CAT) toward hydrogen peroxide $\left(\mathrm{H}_{2} \mathrm{O}_{2}\right)$ with MB-based peroxidase mimics (Figure 4A). ${ }^{29}$ The reverse assay means an inverse relationship between target concentration and signal change. In this RCIA system, CAT/anti-PSA detection antibody functionalized AuNPs were used as enzymatic bioreactors and anti-PSA capture antibody functionalized $\mathrm{MBs}$ as the colorimetric developer. In the presence of target PSA, the sandwiched immunocomplex was formed and CAT could partially consume the $\mathrm{H}_{2} \mathrm{O}_{2}$ in the detection solution, thus reducing the catalytic efficiency of $\mathrm{MB}$ toward $\mathrm{TMB}$ / 




(B)
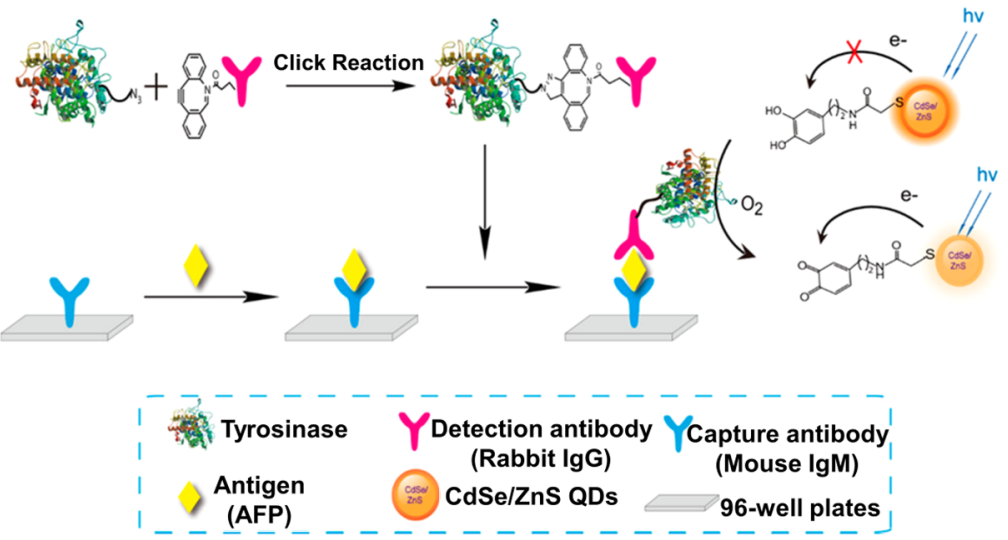

(C)

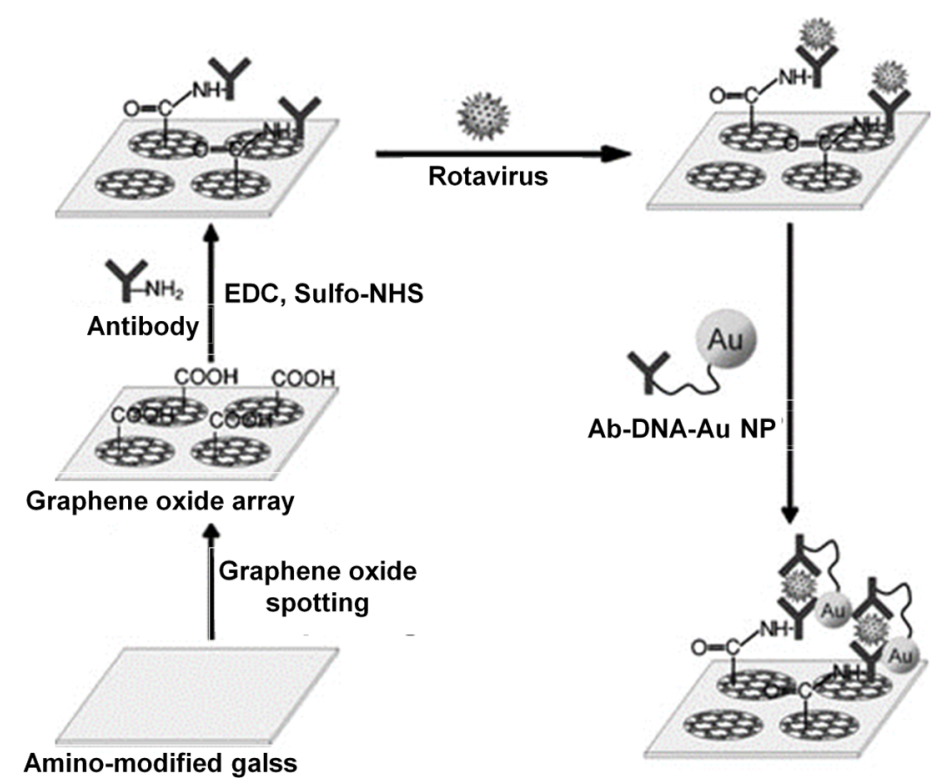

Figure 5. (A) Schematic of the fluorescence immunoassay based on target-induced displacement reaction with cargo (rhodamine B) release from magnetic mesoporous silica nanoparticles (MMSN). (Reprinted from Tang, D. P.; Liu, B. Q.; Niessner, R.; Li, P. W.; Knopp, D. Anal. Chem. 2013, 85, 10589-10596 (ref 45). Copyright 2013 American Chemical Society.) (B) Schematic illustration of the redox-mediated indirect fluorescence immunoassay for detection of disease biomarker based on dopamine (DA)-functionalized CdSe/ZnS quantum dots (QDs). (Reprinted from Zhang, W. H.; Ma, W.; Long, Y. T. Anal. Chem. 2016, 88 (10), 5131-5136 (ref 48). Copyright 2016 American Chemical Society.) (C) Schematic illustration of the GO-based immunosensor. (Reprinted from A Graphene Oxide Based Immuno-biosensor for Pathogen Detection, Jung, J. H.; Cheon, D. S.; Liu, F.; Lee, K. B.; Seo, T. S. Angew. Chem. Int. Ed., Vol. 49, Issue 33 (ref 49). Copyright 2010 Wiley.)

$\mathrm{H}_{2} \mathrm{O}_{2}$. As a result, the visible color was weakened, and the absorbance was decreased. By monitoring the signal change in the absorbance, this RCIA strategy exhibited a wide dynamic range $\left(0.05-20 \mathrm{ng} \mathrm{mL}^{-1}\right)$ toward PSA with a detection limit of $0.03 \mathrm{ng} \mathrm{mL}^{-1}$.

Lai et al. discovered that $\mathrm{H}_{2} \mathrm{O}_{2}$ (the catalytic product of GOx activity on glucose) in acidic solution has the ability to catalytically oxidize iron(II) to iron(III), which can chelate with squaric acid (SQA) to form a SQA-iron(III) complex (Figure
4B). ${ }^{19}$ This SQA-iron(III) complex changed the color of the detection solution from bluish purple to bluish red with increasing absorbance due to the increase in iron(III) concentration. On the basis of this phenomenon, PSA was used as a model analyte, monoclonal antihuman PSA antibody (mAb1) functionalized $\mathrm{MBs}$ (MB-Ab1) acted as the immunosensing probe for specific capture of the target PSA, and GOx and polyclonal anti-PSA (pAb2) antibody functionalized AuNPs (GOx-AuNP-pAb2) were used as the signal 
(A)

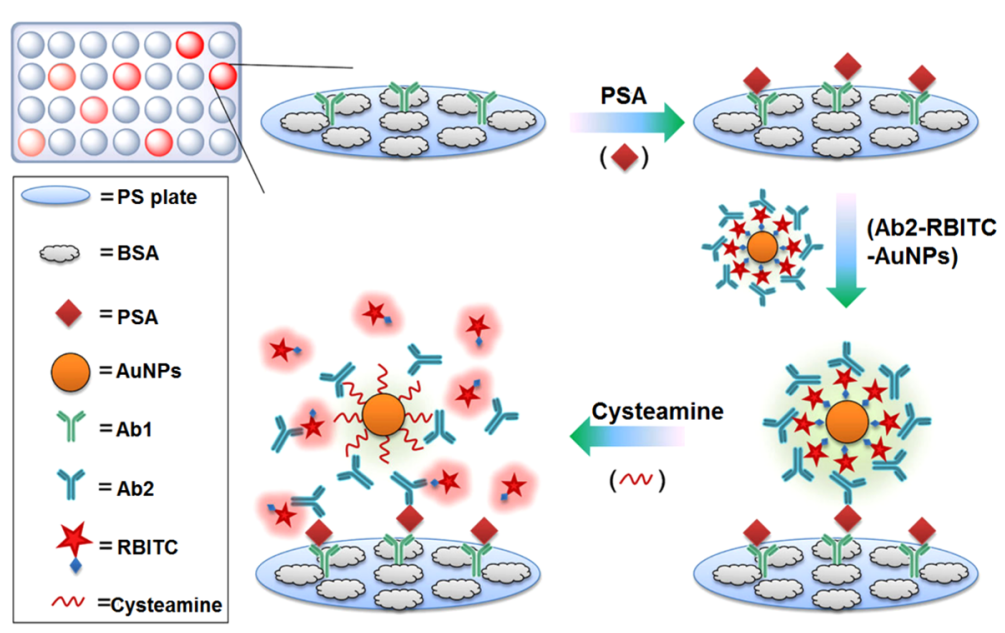

(B)
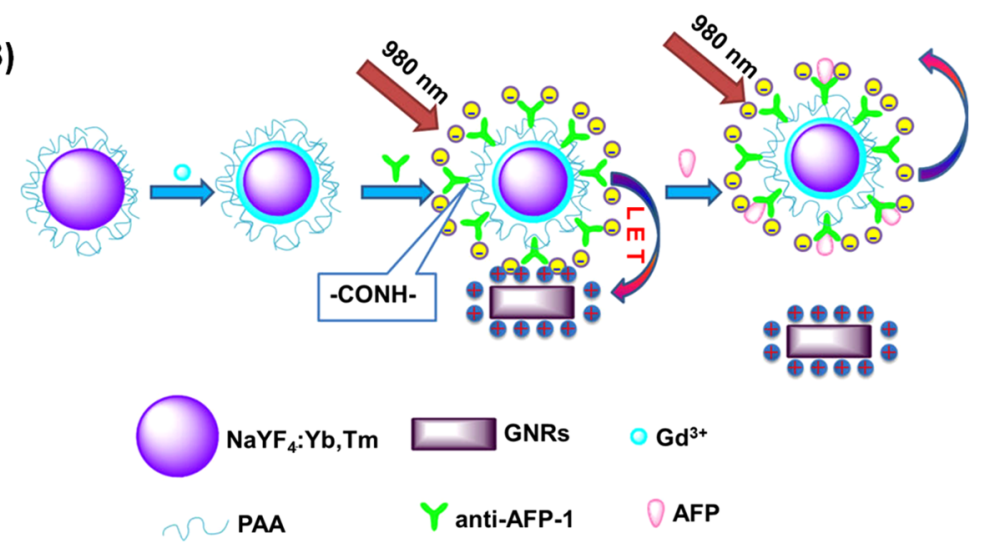

(C)



Figure 6. (A) Schematic illustration of the fluorescence-activated immunoassay for sensitive detection of PSA. (Reprinted from Liu, D. B.; Huang, X. L.; Wang, Z. T.; Jin, A.; Sun, X. L.; Zhu, L.; Wang, F.; Ma, Y.; Niu, G.; Hight Walker, A. R.; Chen, X. Y. ACS Nano 2013, 7, 5568-5576 (ref 50). Copyright 2013 American Chemical Society.) (B) Schematic illustration of determination of AFP based on near-infrared luminescence energy transfer (LET) from carboxyl functionalized $\mathrm{NaYF}_{4}: \mathrm{Yb}, \mathrm{Tm}-\mathrm{NaGdF}_{4}$ core-shell upconverting nanoparticles (UCNPs) to gold nanorods (GNRs). (Reprinted from Chen, H. Q.; Guan, Y. Y.; Wang, S. Z.; Ji, Y.; Gong, M. Q.; Wang, L. Langmuir 2014, 30, 13085-13091 (ref 51). Copyright 2014 American Chemical Society.) (C) Fluorogenic immunoassay based on enzymatic growth of quantum dots (QDs) for detection of anti-BSA antibody. (Reprinted from Malashikhina, N.; Garai-Ibabe, G.; Pavlov, V. Anal. Chem. 2013, 85, 6866-6870 (ref 52). Copyright 2013 American Chemical Society.).

transduction tag. In the presence of target PSA, the GOxAuNP-pAb2 conjugates can be captured through the immunoreaction. As a result, the complexed GOx can catalyze glucose to produce gluconic acid and hydrogen peroxide, accompanied by catalysis of the SQA-iron(II) system to produce the colored SQA-iron(III) complex. In this case, the change in absorbance intensity was indirectly dependent on the concentration of PSA in the sample. Under optimal conditions, this sensor showed a good linear relationship in the range from $1.0 \mathrm{pg} \mathrm{mL}^{-1}$ to $30 \mathrm{ng}$ $\mathrm{mL}^{-1}$ with high sensitivity $\left(0.5 \mathrm{pg} \mathrm{mL}^{-1}\right)$.

Fluorescence Sensing Strategies. Because of their excellent fluorescence properties, various nanomaterials have been widely used in the design of fluorescence nanosensor systems, including noble metal nanoparticles, quantum dots (QDs), upconversion nanomaterials, and graphene oxides (GO). Generally, a fluorescence nanosensor system consists of two functional components: the recognition element, which 
is used to provide specific binding with the target, and the fluorescent nanotransducer component, which is used for signaling the binding event. These two components determine the performance of the nanosensor in terms of selectivity and sensitivity. According to the fluorescent properties of the nanomaterials and the requirement of the assay, nanomaterialbased fluorescent sensors can be typically classified into two types: "turn off" and "turn on" strategies.

"Turn off" Type. The ability of target or target-ligand complexes to quench the fluorescence of fluorophores (nanomaterial or dye) provides an intrinsic feature for the operation of turn off sensors. For instance, based on the glucose-concanavalin A (Con A)-mannose epitope displacement assay format, a target-induced displacement reaction accompanying glucose-responsive rhodamine $\mathrm{B}(\mathrm{RB})$ release from biotinylated Con A-gated magnetic mesoporous silica nanoparticles (MMSN) was developed for sensitive monitoring of AFB1 (Figure 5A). ${ }^{45}$ To construct this assay system, mannose-functionalized MMSN was loaded with $\mathrm{RB}$ and capped with biotinylated Con A and then conjugated with biotinylated monoclonal anti-AFB1 capture antibody through the streptavidin-biotin chemistry, while invertase and bovine serum albumin-AFB1 (AFB1-BSA) functionalized AuNP was used as the trace tag. In the presence of AFB1, the target AFB1 competed with the functionalized AFB1-BSA on the gold nanoparticle for the labeled anti-AFB1 antibody on the MMSN. With the addition of sucrose, the immobilized invertase hydrolyzed the sucrose to produce glucose, which could compete with the mannose for Con A and displace the Con Abased complex from the MMSN, resulting in opening of the molecular gates of MMSN and releasing the entrapped $R B$ from the pores. By monitoring the amount of released $\mathrm{RB}$, the concentration of target AFB1 in the sample was determined with a detection limit of $8 \mathrm{pg} \mathrm{mL} \mathrm{m}^{-1}$. Knopp's group also designed a magnetic bead-based fluorescent immunoassay for AFB1 using AuNP-catalyzed uranine reduction for signal amplification. ${ }^{46}$ Due to the high catalytic activity of AuNP toward uranine, the developed fluorescence system exhibited a high sensitivity for AFB1 with a detection limit of $17.1 \mathrm{pg}$ $\mathrm{mL}^{-1}$. In addition, they synthesized silica-coated upconverting nanoparticles (UCNPs), which were used for the conjugation to a secondary antimouse IgG antibodies. ${ }^{47}$ The UCNPs could emit light of shorter wavelengths (anti-Stokes emission) when they were excited by near-infrared light and thus strongly reduce optical background interference. Owing to the advantages of UCNPs, the UCNPs-based immunoassay exhibited a high sensitivity for the detection of diclofenac $\left(0.05 \mathrm{ng} \mathrm{mL}^{-1}\right)$ without the need of enzyme-mediated signal amplification.

Zhang et al. developed a redox-mediated indirect fluorescence immunoassay for detecting the disease biomarker $\alpha$ fetoprotein (AFP) in a model based on dopamine (DA)immobilized CdSe/ZnS quantum dots (QDs) (Figure 5B). ${ }^{48}$ In this system, tyrosinase conjugated with the detection antibody was used as a bridge linking the QD fluorescence signals with the concentration of target disease biomarkers; the tyrosinase could catalyze enzymatic oxidation of DA to DA-quinone, resulting in fluorescence quenching in the presence of the analyte. Using this method, the detection limit for AFP was as low as $10 \mathrm{pM}$. This work provides a new pathway for the detection of disease biomarkers by RMFIA and has good potential for other applications.
Jung et al. demonstrated a graphene oxide (GO)-based immuno-biosensor for detecting rotavirus as a pathogen model (Figure 5C). ${ }^{49}$ GO has the property of photoluminescence with a quantum yield of $70.3 \%$ due to the electron-hole pairs localized within small $\mathrm{sp}^{2}$ carbon domains embedded in a $\mathrm{sp}^{3}$ matrix. In this study, the negatively charged GO is bound to the positive surface through an electrostatic interaction. The capture antibodies for rotavirus were conjugated to the GO array through a carbodiimide-assisted amidation reaction. The antibody-DNA-AuNP complexes were synthesized based on phosphoramidite chemistry, and the DNA molecule provided facile control of the distance between the $\mathrm{Ab}$ and AuNPs, such that the AuNPs were placed close to the GO surface. In the presence of rotavirus, $\mathrm{Ab}-\mathrm{DNA}-\mathrm{AuNP}$ complexes were indirectly captured on the GO surface through specific antigen-antibody interaction, resulting in a reduction in the fluorescence emission of $\mathrm{GO}$ by fluorescence resonance energy transfer (FRET) between the GO sheets and AuNPs and enabling identification of pathogenic target cells. The detection limit of this method was $10^{5} \mathrm{pfu} \mathrm{mL}^{-1}$, which is comparable to the LOD value of a conventional ELISA assay. This GO-based immuno-biosensor platform can be expanded to a microarray format assay for multiple target analysis.

"Turn on" Type. Sensors that show fluorescence enhancement upon binding to the analyst are generally preferred because they allow a lower detection limit. Liu et al. explored an AuNP-based fluorescence-activated immunoassay for sensing ultralow levels of cancer biomarker (PSA) in patient serum samples (Figure 6A). ${ }^{50}$ Here, rhodamine B isothiocyanate (RBITC) was used as the model fluorescent dye and the donor, and AuNPs were employed as the quencher and the acceptor. In this study, each AuNP was labeled with thousands of RBITC molecules to form RBITC-AuNPs conjugates due to the high surface area-to-volume ratio of the AuNPs and consequently the fluorescence of RBITC was quenched by AuNPs via the nanoparticle surface energy transfer (NSET) effect. The RBITC layer of the nanoconjugates could bind with detection antibodies (Ab2) through electrostatic interactions because of the positively charged quaternary ammonium groups on RBITC. Thus, in the presence of target PSA, the Ab2RBITC-AuNP conjugates were captured onto the substrate and the fluorescence of RBITC on the AuNP surface was highly quenched. After addition of cysteamine into this detection system, the labeled RBITC molecules were competitively displaced from the AuNP surface, causing significant restoration of RBITC fluorescence. Therefore, the intensity of the recovered fluorescence could be used for quantitative determination of the concentration of target PSA in serum samples. The detection limit of this developed probe for PSA was as low as $0.032 \mathrm{pg} \mathrm{mL}^{-1}$, which is at least 2 orders of magnitude lower than the conventional fluorescent immunoassays and HRP-based immunoassays.

Chen et al. fabricated a turn-on homogeneous immunoassay based on a near-infrared (NIR) luminescence energy transfer (LET) system from carboxyl functionalized $\mathrm{NaYF}_{4}: \mathrm{Yb}, \mathrm{Tm}-$ $\mathrm{NaGdF}_{4}$ core-shell upconverting nanoparticles (UCNPs) to gold nanorods (GNRs) for the sensitive and selective determination of $\alpha$-fetoprotein (AFP, a cancer marker) in human serum samples (Figure 6B). ${ }^{51}$ The carboxyl functionalized UCNPs, whose emission peak appeared at a NIR wavelength $(\sim 804 \mathrm{~nm})$ with high photoluminescence efficiency, acted as the donor and were conjugated with the antiAFP antibody (Ab1). GNRs were synthesized and acted as the 
(A)

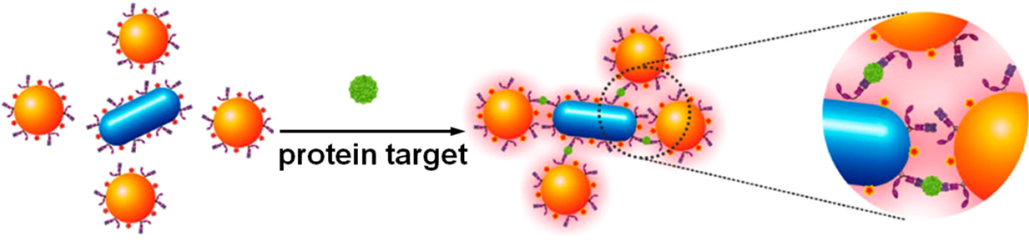

(B)

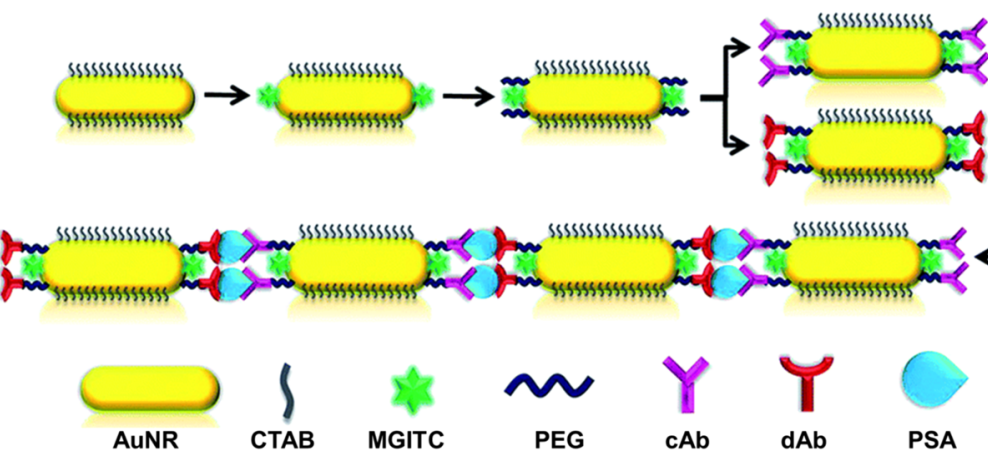

(C)

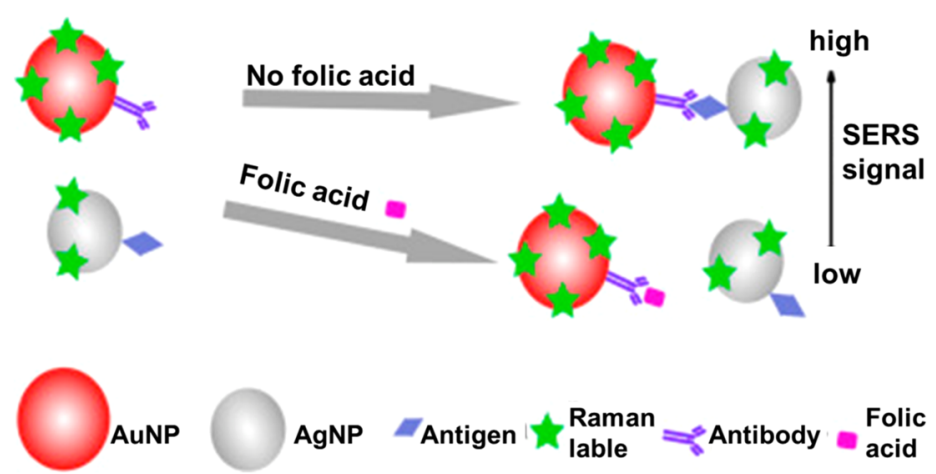

Figure 7. (A) Schematic of single-step SERS immunoassay via target-controlled assembly of SERS nanoparticles. (Reprinted from Wang, Y.; Tang, L. J.; Jiang, J. H. Anal. Chem. 2013, 85, 9213-9220 (ref 54). Copyright 2013 American Chemical Society.) (B) Schematic illustration of the end-to-end assembly of AuNRs by antibody-antigen interactions for PSA detection. (Reprinted from Yang, A. Q.; Wang, D.; Wang, X.; Han, Y.; Ke, X. B.; Wang, H. J.; Zhou, X.; Ren, L. RSC Adv. 2015, 5, 38354-38360 (ref 55), with permission of The Royal Society of Chemistry.) (C) Schematic of the homogeneous SERS immunoassay for detection of FA based on AuNP-AgNP heterodimers. (Reprinted from Biosens. Bioelectron., Vol. 75, Wu, X. L.; Chen, X.; Gao, F. L.; Ma, W.; Xu, L. G.; Kuang, H.; Li, A. K.; Xu, C. L. SERS encoded nanoparticle heterodimers for the ultrasensitive detection of folic acid, pp. 55-58 (ref 56), Copyright 2016, with the permission from Elsevier.)

acceptor owing to their high absorption band around $790 \mathrm{~nm}$, which overlapped with the UCNP emission. The negatively charged donor could interact with the positively charged acceptor via electrostatic interactions, bringing them into close proximity and resulting in LET with a quenching phenomenon. However, in the presence of AFP antigens, the binding affinity between AFP and Ab1 was stronger than the electrostatic interactions, which displaced the energy acceptors from the energy donors thus destroying luminescence energy transfer and restoring the luminescence. In this study, the NIR emission of $\mathrm{NaYF}_{4}: \mathrm{Yb}, \mathrm{Tm}-\mathrm{NaGdF}_{4}$ core-shell nanoparticles at $804 \mathrm{~nm}$ was used as the detection signal. Under optimal conditions, a linear range from 0.18 to $11.44 \mathrm{ng} \mathrm{mL}^{-1}$ AFP was obtained with a detection limit of $0.16 \mathrm{ng} / \mathrm{mL}$.

Malashikhina et al. designed a fluorogenic immunoassay for target antibody detection based on in situ growth of fluorescence semiconductor quantum dots (CdS QDs) (Figure 6C) ${ }^{52}$ In this work, the substrate of alkaline phosphatase (ALP) was the conventional chromogenic substrate pNitrophenyl phosphate (pNPP), which could be hydrolyzed to produce p-nitrophenol (pNP) and phosphate ions. With the addition of $\mathrm{Cd}^{2+}$ and $\mathrm{S}^{2-}$ ions, phosphate-stabilized fluorescent CdS QDs could be formed in situ. Thus, by using ALP-labeled antibody, the concentration of analyte can be detected through the formation of CdS QDs. This method could selectively detect the analyte antibody in a linear range up to $10 \mathrm{ng} \mathrm{mL}^{-1}$ with a detection limit as low as $0.4 \mathrm{ng} \mathrm{mL}^{-1}$, which was 1 order of magnitude lower than that of the standard method based on enzymatic hydrolysis of the chromogenic substrate pNPP.

Long et al. presented a hapten-grafted graphene-based homogeneous competitive fluoroimmunosensor for sensitive detection of bisphenol A (BPA). ${ }^{53}$ Here, the hapten-grafted graphene nanosheets acted as the immunological recognition of fluorescence-labeled antibody as well as a fluorescence quencher because of the excellent quenching capability of graphene toward organic dyes. The structure of hapten-grafted graphene has the advantages of avoiding loss of activity and/or selectivity of biomolecules immobilized onto the graphene surface, thus improving the binding affinity between biomolecules and the specific antibody. Furthermore, the sandwich structure formed by functionalized graphene nanosheets and fluorescence-labeled antibody increases the quenching efficiency of graphene for the organic dye, thereby providing high signal-to-background ratios and high sensitivity for BPA detection. 
(A) (a)

(b)

(c)

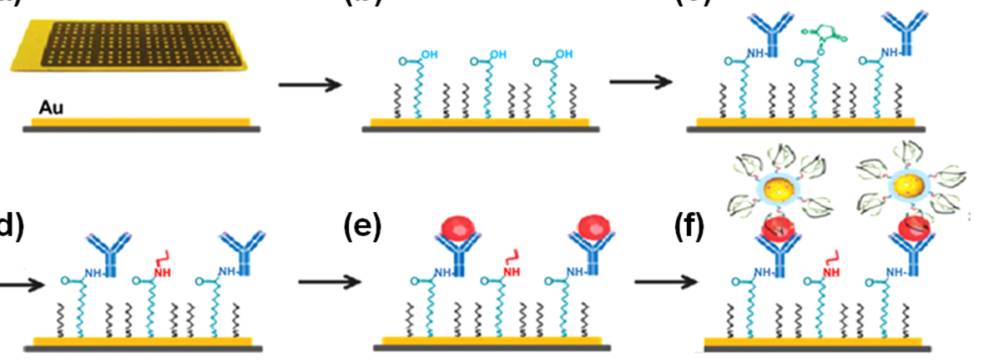

(B) (a)

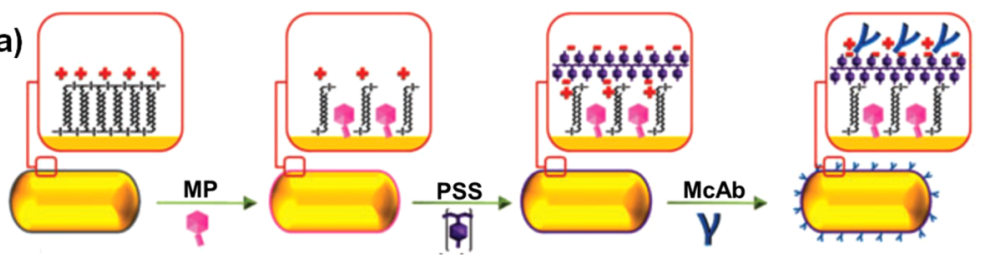

(b) (iv) GNRs/MP/PSS/McAb

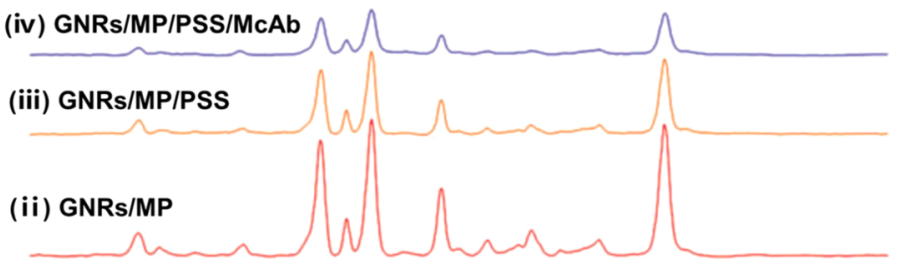

(i ) Only GNRs

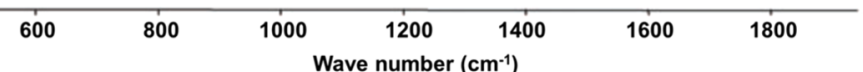

(C) (a)

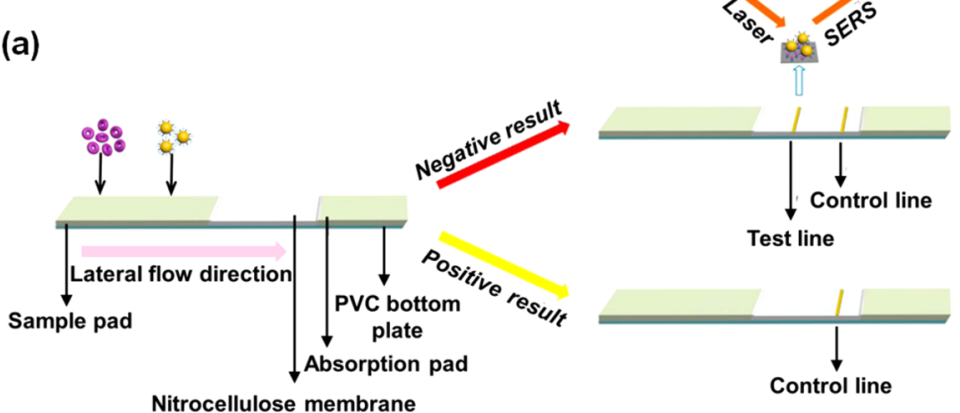

Nitrocellulose membrane

Control line

Phenylethanolamine A AuMBA @Ag-Ab probe 8PA-BSA

(b)

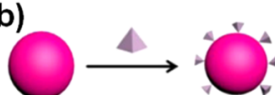

$\underset{\mathrm{AgNO}_{3}}{\longrightarrow}$
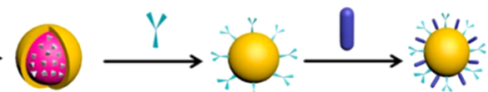

Au nanoparticle

$\triangle \mathrm{MBA}$

AuMBA@Ag nanoparticle

Antibody

BSA

Figure 8. (A) Schematic mechanism of SERS-based sandwich immunoassay using DNA/silica-encapsulated hollow gold nanospheres (SEHGNs) and the gold-patterned microarray well. (Adapted from Ko, J.; Lee, S.; Lee, E. K.; Chang, S. I.; Chen, L. X.; Yoon, S. Y.; Choo, J. B. Phys. Chem. Chem. Phys. 2013, 15, 5379-5385 (ref 57), with permission of The PCCP Owner Societies.) (B) (a) Schematic diagram of the process for layer-bylayer assembly of antibodies onto the surface of a nanorod through electrostatic interactions and (b) corresponding SERS spectra for each process: (i) GNRs/MP; (ii) PSS powder only; (iii) GNPs/MP/PSS; (iv) GNPs/MP/PSS/McAb. Notes: GNR = gold nanorod; MP = 4-mercaptopyridine; PSS = poly(sodium 4-styrene-sulfonate); McAb = monoclonal antirabbit antibody. (Reprinted from Park, H.; Lee, S.; Chen, L. X.; Lee, E. K.; Shin, S. Y.; Lee, Y. H.; Son, S. W.; Oh, C. H.; Song, J. M.; Kang, S. H.; Choo, J. B. Phys. Chem. Chem. Phys. 2009, 11, 7444-7449 (ref 58), with permission of The PCCP Owner Societies.) (C) (a) Schematic illustrations of the structure of the immunochromatographic assay (ICA) strip and the protocol of SERS-based ICA for quantitative detection of PA; (b) preparation of the Au ${ }^{\mathrm{MBA}} @ \mathrm{Ag}-\mathrm{Ab}$ probe. (Reprinted from Li, M. X.; Yang, H.; Li, S. Q.; Zhao, K.; Li, J. G.; Jiang, D. N.; Sun, L. L.; Deng, A. P. J. Agric. Food Chem. 2014, 62, 10896-10902 (ref 59). Copyright 2014 American Chemical Society.)

Surface-Enhanced Raman Scattering Strategies. SERS has the advantages of fingerprint information, in situ non- invasive detection, and more importantly, ultrahigh sensitivity up to $10^{14}$ that is suitable for single-molecule detection. 
Consequently, SERS nanoprobes have been widely applied to immunoassays, which are typically designed as analyte-induced SERS nanoprobe aggregation/antiaggregation and SERSnanoprobe based optical labeling approaches.

Analyte-Induced SERS Nanoprobe Aggregation/Antiaggregation. The SERS substrates (e.g., Au/Ag nanoparticles) can offer a stronger Raman enhancement than individual nanostructures due to the formation of hotspots in noble metal nanoparticle junctions. A single-step, multiplexed, homogeneous SERS immunoassay platform for the sensitive detection of protein targets based on controlled assembly of SERS nanoparticles was reported (Figure 7A). ${ }^{54}$ The essential design feature of this strategy is that the SERS substrates (AuNPs or AuNRs) were codecorated by specifically orientated immobilized antibody half-fragments, nonfluorescent Raman-active dyes, and passivating proteins. This construct of SERS nanoparticles significantly decreased the interparticle distance and could provide multicolor Raman fingerprint coding with high signal-to-noise ratio. The assembly of SERS nanoparticles was realized by the sandwiched antibody-antigen interactions with a strong SERS signal. This platform was successfully applied for multiplexed quantification of three proteins and thus represents a potential tool for early detection of disease biomarkers. Yang et al. reported a highly sensitive and selective SERS strategy for the detection of PSA based on the fabrication of end-to-end (EE) gold nanorod (AuNR) assemblies (Figure 7B). ${ }^{55}$ In this study, two different antibody functionalized AuNRs were used as Raman reporters. The biorecognition between target antigen (PSA) and antibody assisted the EE assembly of AuNRs, which further resulted in the formation of numerous "hot spots" in the gap between AuNRs. The LOD was found to be as low as $0.01 \mathrm{ng} \mathrm{mL^{-1 }}$ with a linear range of 0.05 to $100 \mathrm{ng} \mathrm{mL}^{-1}$. This SERS-based immunoassay for PSA detection was also successfully applied to diluted human serum samples, showing great potential for early diagnosis of diseases in clinical application. Wu et al. developed a homogeneous SERS immunoassay for ultrasensitive detection of folic acid (FA) by controlling the assembly of AuNP-AgNP heterodimers through antigen-antibody immunoreaction (Figure 7C). ${ }^{56}$ In the absence of target FA, the antibody (anti-FA)/ Raman reporter-labeled AuNPs and the antigen (FA-BSA conjugates)/Raman reporter-labeled AgNPs could assemble completely, forming heterodimers and showing strong SERS intensity. However, in the presence of FA, the free FA could compete with the AgNP-labeled antigen for binding with the AuNP-labeled antibody, thus reducing the assembly of heterodimers. Consequently, the SERS intensity was decreased. The concentration of target FA could be revealed by the significantly reduced Raman intensity of the Raman reporter. This method could detect FA at concentrations as low as 0.86 pg $\mathrm{mL}^{-1}$ with a wide linear range from 0.005 to $1 \mathrm{ng} \mathrm{mL} \mathrm{m}^{-1}$.

SERS-Nanoprobe-Based Optical Labeling. Another approach to SERS-based immunoassay is direct use of the SERS nanoprobe in optical labeling. For example, a SERS-based sandwich immunoassay using DNA aptamers/silica-encapsulated hollow gold nanospheres (SEHGNs) as SERS tags was developed for sensitive detection of the tumor marker vascular endothelial growth factor (VEGF) (Figure 8A). ${ }^{57}$ In this work, DNA aptamer-conjugated SEHGN was used as the SERSencoding nanoprobe instead of detection antibodies, and a hybrid gold-patterned microarray was used as the SERS substrate. The SEHGNs not only improved the stability and biocompatibility of HGN but also prevented desorption of
Raman reporters as well as adsorption of external species. Moreover, the HGNs ensure a reproducible and high enhancement effect on individual particles based on their ability to localize surface electromagnetic fields through pinholes in the hollow particle structures. The detection sensitivity of this method was 2 or 3 orders of magnitude higher than that of the conventional ELISA method. SERS imaging is another good method of signal measurement. Choo's group developed a SERS imaging strategy for detection of HER2overexpressing MCF7 breast cancer cells using antibodyconjugated gold nanorods (Figure $8 \mathrm{~B}$ ). ${ }^{58}$ Here, they used SERS-active Raman reporter and antirabbit IgG-conjugated GNRs as functional nanoprobes for the targeting and imaging of specific HER2 markers expressed on the surface membrane of MCF7 cells. Their results demonstrated that the functionalized GNRs could be used as highly sensitive molecular imaging probes in biomedical diagnostics. In addition, lateral flow assays (LFAs), or immunochromatographic test strips, have attracted enormous attention because of their simplicity, rapidity, low cost, user-friendly platform, and low interference due to chromatographic separation. $\mathrm{Li}$ et al. presented a novel SERS-based immunochromatographic assay for the ultrasensitive quantitative detection of phenylethanolamine A (PA) (Figure 8C). ${ }^{59}$ To construct this system, a new probe was designed using $\mathrm{Au} / \mathrm{Ag}$ core-shell nanoparticles labeled with polyclonal antibody against PA sandwiched with 4mercaptobenzoic acid (MBA, a Raman reporter) ( $\mathrm{Au}^{\mathrm{MBA}} @ \mathrm{Ag}-$ $\mathrm{Ab})$. The test line contained immobilized PA-BSA conjugate, which was designed to compete with target PA in the sample solution for the anti-PA polyclonal antibody, whereas goat antirabbit IgG was immobilized on the control line. Typically, upon addition of the sample solution, the target PA in the sample solution would first bind with the specific antibody binding sites on the surface of the Au ${ }^{\mathrm{MBA}} @ \mathrm{Ag}-\mathrm{Ab}$ probe. This binding reduced the binding sites of the Au ${ }^{\mathrm{MBA}} @ \mathrm{Ag}-\mathrm{Ab}$ probe for PA-BSA, resulting in a weak SERS signal. The excess $\mathrm{Au}^{\mathrm{MBA}} @ \mathrm{Ag}-\mathrm{Ab}$ probe then bound in the control zone producing another line that showed that the biosensor was working properly. Thus, the degree of SERS intensity of $\mathrm{Au}^{\mathrm{MBA}} @ \mathrm{Ag}-\mathrm{Ab}$ on the test line was inversely related to the concentration of PA. The limit of detection of the SERS-based immunochromatographic assay for PA was $0.32 \mathrm{pg} \mathrm{mL}^{-1}$, which was $1-3$ orders of magnitude lower than the values obtained by other immunoassays.

\section{CHALLENGES AND PERSPECTIVES}

Here, we have discussed various kinds of optical nanoprobes that have been designed and successfully applied in immunoassays. With the emergence of new excellent properties of nanomaterials, as well as various novel signal transduction approaches, nanomaterials have paved the way for the development of highly sensitive immunoassays. Especially, molecular biological signal amplification technology such as enzyme-labeled amplification, DNA recycling amplification, or target-induced hybridization chain reaction/repeated primer extension has been introduced. Even though nanomaterialbased immunoassays have a promising future in analyte detection, there are several challenges to the use of optical nanoprobes. In particular, most optical nanoprobe sensors remain at the level of exploring proof-of-concept and cannot be used in real-world applications. Three factors should be considered regarding this issue. The first factor is the active nature of nanomaterials, which are likely to aggregate in ionic 
buffers or be sensitive to a variety of substances in the environment or physiological conditions leading to loss of sensing ability. To solve this problem, researchers can use core-shell or yolk-shell architectures or modifications of specific ligands to improve the performance of the optical nanoprobes. The second issue to be noted is the poor biocompatibility of nanoprobes, which is mainly due to the toxicity of the corresponding nanomaterials in the in vivo immunoassay application. Surface stabilizing and coating materials can be used to reduce the toxicity of nanomaterials. The third issue is how to synthesize nanomaterials with a relatively narrow size distribution because any inhomogeneous distribution of the nanoprobes will reduce the accuracy of the analysis. Despite these challenges, by taking advantage of the excellent optical properties provided by nanomaterials, novel immunoassay instruments such as microfluidic chips and lateral flow strips can be further developed and integrated into mobile phones or computers for real-time monitoring.

\section{AUTHOR INFORMATION}

\section{Corresponding Authors}

*E-mail: lxchen@yic.ac.cn. Tel.: +86-535-2109130. Fax: 86535-2109130 (L.C.).

*E-mail: jbchoo@hanyang.ac.kr. Tel.: +82-31-400-5201. Fax: +82-31-436-8188 (J.C.).

\section{ORCID ${ }^{\circ}$}

Lingxin Chen: 0000-0002-3764-3515

Jaebum Choo: 0000-0003-3864-6459

\section{Notes}

The authors declare no competing financial interest.

\section{Biographies}

Xiuli Fu received her $\mathrm{PhD}$ in 2013 from the Yantai Institute of Coastal Zone, Chinese Academy of Sciences, China, under the supervision of Lingxin Chen. She then moved to the Department of Bionanotechnology at Hanyang University as a postdoctoral researcher working with Jaebum Choo. In the summer of 2015, she moved to the Yantai University as an assistant professor in the Department of Chemistry and Chemical Engineering. Her current research interests focus on exploiting optically active nanoparticles and nanoparticle-based optical sensors.

Lingxin Chen received his $\mathrm{PhD}$ degree in analytical chemistry from the Dalian Institute of Chemical Physics, Chinese Academy of Sciences, Dalian, in 2003. After 2 years of postdoctoral experience at the Department of Chemistry, Tsinghua University, Beijing, he joined the Department of Applied Chemistry, Hanyang University, Korea in 2006, first as a BK21 researcher and then as a research professor. In 2009, he joined the Yantai Institute of Coastal Zone Research, Chinese Academy of Sciences, Yantai as a professor. His research interests include the study of novel properties of materials such as functionalized nanoparticles for developing nanoscale biochemical analysis methods and molecular imprinting-based sample pretreatment technology.

Jaebum Choo was awarded a $\mathrm{PhD}$ from Texas A\&M University, College Station, TX, USA, in 1994. He is a Professor in Hanyang University, Department of Bionanotechnology. His current research interests focus on early disease diagnosis using immunoanalysis in a microfluidic channel, development of optofluidic biosensors for sensitive biomarker detection, highly sensitive biological detection using nanoscale optical detection technology, development of a highly sensitive laser-induced optical microscopic system, high-resolution fluorescence imaging of cancer cells using QD nanocrystals, surface- enhanced Raman imaging of cancer cells using functional nanoprobes, and the application of optical phase contrast imaging for early cancer diagnosis.

\section{ACKNOWLEDGMENTS}

This work was financially supported by the National Natural Science Foundation of China (grant nos. 21275158 and 21575159) and the National Research Foundation of Korea (grant nos. 2008-0061891 and 2009-00426).

\section{REFERENCES}

(1) Lei, J. P.; Ju, H. X. Chem. Soc. Rev. 2012, 41, 2122-2134.

(2) Zhang, Y.; Guo, Y. M.; Xianyu, Y. L.; Chen, W. W.; Zhao, Y. Y.; Jiang, X. Y. Adv. Mater. 2013, 25, 3802-3819.

(3) Wang, Y. Q.; Yan, B.; Chen, L. X. Chem. Rev. 2013, 113, 13911428.

(4) Saha, K.; Agasti, S. S.; Kim, C.; Li, X. N.; Rotello, V. M. Chem. Rev. 2012, 112, 2739-2779.

(5) Doria, G.; Conde, J.; Veigas, B.; Giestas, L.; Almeida, C.; Assunção, M.; Rosa, J.; Baptista, P. V. Sensors 2012, 12, 1657-1687.

(6) Wu, P.; Yan, X. P. Chem. Soc. Rev. 2013, 42, 5489-5521.

(7) Kershaw, S. V.; Susha, A. S.; Rogach, A. L. Chem. Soc. Rev. 2013 42, 3033-3087.

(8) Freeman, R.; Willner, I. Chem. Soc. Rev. 2012, 41, 4067-4085.

(9) Liu, Y. S.; Tu, D. T.; Zhu, H. M.; Chen, X. Y. Chem. Soc. Rev. 2013, 42, 6924-6958.

(10) Zhou, J.; Liu, Z.; Li, F. Y. Chem. Soc. Rev. 2012, 41, 1323-1349.

(11) Wen, J.; Xu, Y. Q.; Li, H. J.; Lu, A. P.; Sun, S. G. Chem. Commun. 2015, 51, 11346-11358.

(12) Liu, Y. X.; Dong, X. C.; Chen, P. Chem. Soc. Rev. 2012, 41, 2283-2307.

(13) Mayer, K. M.; Hafner, J. H. Chem. Rev. 2011, 111, 3828-3857.

(14) Zhang, C. M.; Lin, J. Chem. Soc. Rev. 2012, 41, 7938-7961.

(15) Choi, S. M.; Dickson, R. M.; Yu, J. H. Chem. Soc. Rev. 2012, 41, 1867-1891.

(16) Sapsford, K. E.; Algar, W. R.; Berti, L.; Gemmill, K. B.; Casey, B. J.; Oh, E.; Stewart, M. H.; Medintz, I. L. Chem. Rev. 2013, 113, 19042074.

(17) Zeng, S. W.; Yong, K. T.; Roy, I.; Dinh, X. Q.; Yu, X.; Luan, F. Plasmonics 2011, 6, 491-506.

(18) Park, J.; Shin, J. H.; Park, J. K. Anal. Chem. 2016, 88, 37813788.

(19) Lai, W. Q.; Tang, D. P.; Zhuang, J. Y.; Chen, G. N.; Yang, H. H. Anal. Chem. 2014, 86, 5061-5068.

(20) Hou, L.; Tang, Y.; Xu, M. D.; Gao, Z. Q.; Tang, D. P. Anal. Chem. 2014, 86, 8352-8358.

(21) Song, C. Y.; Min, L. H.; Zhou, N.; Yang, Y. J.; Yang, B. Y.; Zhang, L.; Su, S.; Wang, L. H. RSC Adv. 2014, 4, 41666-41669.

(22) Lee, S.; Chon, H.; Lee, M.; Choo, J. B.; Shin, S. Y.; Lee, Y. H.; Rhyu, I. J.; Son, S. W.; Oh, C. H. Biosens. Bioelectron. 2009, 24, 22602263.

(23) Qian, X. M.; Peng, X. H.; Ansari, D. O.; Yin-Goen, Q. Q.; Chen, G. Z.; Shin, D. M.; Yang, L.; Young, A. N.; Wang, M. D.; Nie, S. M. Nat. Biotechnol. 2008, 26, 83-90.

(24) Li, H.; Chen, C. Y.; Wei, X.; Qiang, W. B.; Li, Z. H.; Cheng, Q.; $\mathrm{Xu}, \mathrm{D}$. K. Anal. Chem. 2012, 84, 8656-8662.

(25) Lin, H. J.; Liu, Y. F.; Huo, J. R.; Zhang, A. H.; Pan, Y. T.; Bai, H. H.; Jiao, Z.; Fang, T.; Wang, X.; Cai, Y.; Wang, Q. M.; Zhang, Y. J.; Qian, X. H. Anal. Chem. 2013, 85, 6228-6232.

(26) Zhang, Q. Z.; Zhao, B.; Yan, J.; Song, S. P.; Min, R.; Fan, C. H. Anal. Chem. 2011, 83, 9191-9196.

(27) Hu, G. S.; Sheng, W.; Zhang, Y.; Wang, J. P.; Wu, X. N.; Wang, S. J. Agric. Food Chem. 2016, 64 (19), 3908-3915.

(28) Qu, Z. Y.; Xu, H.; Xu, P.; Chen, K. M.; Mu, R.; Fu, J. P.; Gu, H. C. Anal. Chem. 2014, 86, 9367-9371.

(29) Gao, Z. Q.; Xu, M. D.; Hou, L.; Chen, G. N.; Tang, D. P. Anal. Chem. 2013, 85, 6945-6952. 
(30) Gao, R. K.; Cheng, Z. Y.; deMello, A. J.; Choo, J. B. Lab Chip 2016, 16, 1022-1029.

(31) Yoon, J.; Choi, N.; Ko, J.; Kim, K.; Lee, S.; Choo, J. B. Biosens. Bioelectron. 2013, 47, 62-67.

(32) Gao, R. K.; Ko, J.; Cha, K.; Jeon, J. H.; Rhie, G. E.; Choi, J.; deMello, A. J.; Choo, J. B. Biosens. Bioelectron. 2015, 72, 230-236.

(33) Chen, L.; Zhang, X. W.; Zhou, G. H.; Xiang, X.; Ji, X. H.; Zheng,

Z. H.; He, Z. K.; Wang, H. Z. Anal. Chem. 2012, 84, 3200-3207.

(34) Morales-Narváez, E.; Naghdi, T.; Zor, E.; Merkoci, A. Anal. Chem. 2015, 87, 8573-8577.

(35) Nam, J. M.; Thaxton, C. S.; Mirkin, C. A. Science 2003, 301, $1884-1886$

(36) Thaxton, C. S.; Elghanian, R.; Thomas, A. D.; Stoeva, S. I.; Lee, J.; Smith, N. D.; Schaeffer, A. J.; Klocker, H.; Horninger, W.; Bartsch, G.; Mirkin, C. A. Proc. Natl. Acad. Sci. U. S. A. 2009, 106, 1843718442.

(37) Kim, D.; Daniel, W. L.; Mirkin, C. A. Anal. Chem. 2009, 81, 9183-9187.

(38) Liu, D. B.; Wang, Z. T.; Jin, A.; Huang, X. L.; Sun, X. L.; Wang, F.; Yan, Q.; Ge, S. X.; Xia, N. S.; Niu, G.; Liu, G.; Hight Walker, A. R.; Chen, X. Y. Angew. Chem., Int. Ed. 2013, 52, 14065-14069.

(39) Qu, W. S.; Liu, Y. Y.; Liu, D. B.; Wang, Z.; Jiang, X. Y. Angew. Chem., Int. Ed. 2011, 50, 3442-3445.

(40) de la Rica, R.; Stevens, M. M. Nat. Nanotechnol. 2012, 7, 821824.

(41) Wang, X.; Niessner, R.; Knopp, D. Analyst 2015, 140, 14531458.

(42) Liu, D. B.; Yang, J.; Wang, H. F.; Wang, Z. L.; Huang, X. L.; Wang, Z. T.; Niu, G.; Hight Walker, A. R.; Chen, X. Y. Anal. Chem. 2014, 86, 5800-5806.

(43) Wang, S. S.; Chen, Z. P.; Choo, J. B.; Chen, L. X. Anal. Bioanal. Chem. 2016, 408, 1015-1022.

(44) Zhang, Z. Y.; Chen, Z. P.; Wang, S. S.; Cheng, F. B.; Chen, L. X. ACS Appl. Mater. Interfaces 2015, 7, 27639-27645.

(45) Tang, D. P.; Liu, B. Q.; Niessner, R.; Li, P. W.; Knopp, D. Anal. Chem. 2013, 85, 10589-10596.

(46) Wang, X.; Pauli, J.; Niessner, R.; Resch-Genger, U.; Knopp, D. Analyst 2015, 140, 7305-7312.

(47) Hlaváček, A.; Farka, Z.; Hübner, M.; Horňáková, V.; Němeček, D.; Niessner, R.; Skládal, P.; Knopp, D.; Gorris, H. H. Anal. Chem. 2016, 88, 6011-6017.

(48) Zhang, W. H.; Ma, W.; Long, Y. T. Anal. Chem. 2016, 88 (10), 5131-5136.

(49) Jung, J. H.; Cheon, D. S.; Liu, F.; Lee, K. B.; Seo, T. S. Angew. Chem., Int. Ed. 2010, 49, 5708-5711.

(50) Liu, D. B.; Huang, X. L.; Wang, Z. T.; Jin, A.; Sun, X. L.; Zhu, L.; Wang, F.; Ma, Y.; Niu, G.; Hight Walker, A. R.; Chen, X. Y. ACS Nano 2013, 7, 5568-5576.

(51) Chen, H. Q.; Guan, Y. Y.; Wang, S. Z.; Ji, Y.; Gong, M. Q.; Wang, L. Langmuir 2014, 30, 13085-13091.

(52) Malashikhina, N.; Garai-Ibabe, G.; Pavlov, V. Anal. Chem. 2013, $85,6866-6870$.

(53) Long, F.; Zhu, A.; Shi, H. C.; Wang, H. C. Anal. Chem. 2014, 86, 2862-2866.

(54) Wang, Y.; Tang, L. J.; Jiang, J. H. Anal. Chem. 2013, 85, 92139220.

(55) Yang, A. Q.; Wang, D.; Wang, X.; Han, Y.; Ke, X. B.; Wang, H. J.; Zhou, X.; Ren, L. RSC Adv. 2015, 5, 38354-38360.

(56) Wu, X. L.; Chen, X.; Gao, F. L.; Ma, W.; Xu, L. G.; Kuang, H.; Li, A. K.; Xu, C. L. Biosens. Bioelectron. 2016, 75, 55-58.

(57) Ko, J.; Lee, S.; Lee, E. K.; Chang, S. I.; Chen, L. X.; Yoon, S. Y.; Choo, J. B. Phys. Chem. Chem. Phys. 2013, 15, 5379-5385.

(58) Park, H.; Lee, S.; Chen, L. X.; Lee, E. K.; Shin, S. Y.; Lee, Y. H.; Son, S. W.; Oh, C. H.; Song, J. M.; Kang, S. H.; Choo, J. B. Phys. Chem. Chem. Phys. 2009, 11, 7444-7449.

(59) Li, M. X.; Yang, H.; Li, S. Q.; Zhao, K.; Li, J. G.; Jiang, D. N.; Sun, L. L.; Deng, A. P. J. Agric. Food Chem. 2014, 62, 10896-10902. 